\title{
Incidence of brain tumours in two English counties: a population based study
}

\author{
L H Pobereskin, J B Chadduck
}

\begin{abstract}
Objective-To define the incidence of brain tumours in Devon and Cornwall and to discover which case finding methods are the most fruitful. To examine what happens to patients after the diagnosis of a brain tumour.

Methods-The primary method of case ascertainment was a review of all CT with contrast and MRI of the head performed on the population of Devon and Cornwall between 1 April 1992 and 31 March 1997. Secondary sources included registrations with the South and West Cancer Intelligence Unit and a search for all patients either admitted to hospital with a brain tumour or operated on for a brain tumour during the same period.
\end{abstract}

Results-16 923 scans were reviewed of which 8774 (52\%) were normal. The scan review found 2483 incident intracranial tumours, of which 861 were metastases. Secondary sources of case ascertainment disclosed 46 further cases. Cases were missed by the scan review mainly for technical reasons and only three patients were found who were diagnosed by nonimaging methods. The incidence of primary intracranial tumours standardised to the population of England and Wales was higher than any previously reported (21.04 (17.18-25.62)/100 000 person-years). Overall, $21 \%$ of cases were not admitted to hospital. The categories least likely to be admitted were those with sellar and cranial nerve tumours. Those not admitted to hospital were significantly older than those who were.

Conclusion-One fifth of patients are not admitted to hospital after the diagnosis of a brain tumour and incidence studies must use case finding methods which will capture these cases. An audit of imaging results provides almost complete case ascertainment. This study shows that the incidence of primary brain tumours is considerably higher than previously thought. Official figures from the cancer intelligence units significantly underestimate brain tumour incidence, especially for benign tumours.

(F Neurol Neurosurg Psychiatry 2000;69:464-471)

Keywords: intracranial tumour; epidemiology; incidence

Mr LH Pobereskin

louis.pobereskin@phnt.

louis.poberesk
swest.nhs.uk

Received 25 November 1999 and in revised form

14 April 2000

Accepted 12 May 2000

Accurate information about incidence of disease is important for many reasons. Comparison of rates across time and space can give clues to aetiology and accurate data is needed for informed public health debate and for healthcare resource planning. Definition of disease "clusters", a controversial issue, is impossible without precise knowledge of background incidence.

Information on the incidence of brain tumours in the United Kingdom comes from the tumour registries of the regional cancer intelligence units and from four previous studies. The first two studies took place before the era of $\mathrm{CT}^{1{ }^{2}} \mathrm{~A}$ more recent hospital based study from south Wales reported a crude rate of 5.6/100 000/year. ${ }^{3}$ The most recent population based study from Lothian used multiple sources to identify incident cases and reported a crude rate of 15.3/100 000/year. ${ }^{4}$ The same group reviewed a large number of incidence studies and found that the incidence of tumours was positively related to the number of case finding sources used. ${ }^{5}$ No information was given in either study, however, on which sources were the most informative.

Imaging of the brain has advanced dramatically in the past 20 years and now provides highly accurate information about intracranial structures, with very little perceived risk. This technology is widely available, and its use has become necessary, and in many cases sufficient, for the diagnosis of various intracranial conditions. As a result, over recent years a patient who presents with symptoms of an intracranial tumour is scanned as a matter of routine.

An audit of CT and MRI results would seem to be an ideal way to obtain accurate information about incidence of brain tumours. In the United Kingdom, the National Health Service provides care which is free at the point of use. One advantage of this setting, therefore, is that socioeconomic considerations should not influence the rate of scanning as much as they might in other countries.

The principal aim of this work was to define the incidence of primary intracranial tumours in Devon and Cornwall using an audit of scan results as the main source. This method of case ascertainment allows estimation of the percentage of cases operated on and what proportion were not admitted to hospital. Secondary sources are also examined to see how much they may contribute to case finding.

\section{Methods}

ETHICS 
STUDY AREA

The two counties of Devon and Cornwall have an area of $10347.4 \mathrm{~km}^{2}$. The population in 1991 (1991 United Kingdom census) was 1475643 and in 1996 (mid-census estimate, Office of National Statistics) it was 1504 847, an increase of less than $2 \%$. The population is overwhelmingly white $(99.27 \% ; 1991$ United Kingdom census)

The study area is isolated on a peninsula and is served by five district general hospitals and one tertiary referral centre for neurosurgery. During the study period there were five CT units and three MRI machines in the two counties. Two further imaging units were located within 15 miles of the northeast border of Devon at Bridgewater (MRI) and Taunton (CT). The next closest unit was in Bristol 40 miles away. The vast majority of patients requiring surgery for brain tumours were operated on in Plymouth. A few ( 25/year), mainly children, were operated on in Bristol.

The two counties are in the main rural with no heavy industry. The two major employers are tourism and farming. Large areas of both counties are sparsely populated moorland.

CASE ASCERTAINMENT

The primary source of case ascertainment was a review of scans performed on the study population. The computer systems of the imaging departments at each of the five district general hospitals in the two counties and the two units just to the north east of the Devon border were searched for all patients who had CT with contrast or MRI of the head during the period of 1 April 1992 to 31 March 1997. The study began in September 1996 so in the main it was retrospective. A database was generated with basic demographic data and the date of scanning.

All scan reports were reviewed by one consultant neurosurgeon and one specialist neurosurgical registrar in his 6th year of training. On the basis of the description of any abnormality or the reporting neuroradiologist's opinion, a diagnosis was assigned to each scan. Many reports contained some limited clinical information aiding assignment. Previous scans were available to the reporting radiologist, so examinations which were follow up scans were easily identified.

In a few cases a diagnosis could not be assigned from the scan report and the original scans were retrieved and reviewed.

An incident case was defined as a person who had their first diagnostic scan showing a primary intracranial tumour during the study period. Excluded were patients with scans performed as follow up examinations and all patients with post codes outside Devon and Cornwall. All duplicate entries based on surname and date of birth were removed. To eliminate possible duplication of women who had married and changed surname during the study period a careful check was made for any female with the same first name and date of birth.

Primary tumours were classified in seven categories according to the second World
Health Organisation classification. ${ }^{6}$ Images showing multiple intracranial tumours remote from the dura and those which were accompanied by clinical information mentioning a systemic cancer were considered as metastases.

Secondary sources of case ascertainment included: (1) all registrations during the study period from the South and West Cancer Intelligence Unit coded as primary brain tumours in people with Devon and Cornwall post codes; (2) search of the operative database in Plymouth for all patients coded as having had removal of an intracranial tumour; (3) search for all patients in the histopathology database at Plymouth coded as having intracranial tumours $^{6}$; (4) search of the patient administration system database for all patients admitted to hospital in Plymouth or Bristol with codes indicating a possible intracranial tumour.

\section{VERIFICATION}

Once all scan reports had been reviewed and a diagnosis assigned, the results were checked against the histopathology database at Plymouth and the details of all patients with Devon and Cornwall post codes operated on in Bristol. Where the histological diagnosis differed from the one assigned by the scan review, the histologically correct diagnosis was substituted.

Two checks were made to ensure that cases incident before the study period were not included. For cases classified as primary tumours all pre-1992 imaging was reviewed. The Department of Neurosurgery at Plymouth maintains a computerised database of all operations which have been carried out since the inception of the unit in 1964. All records were cross checked against this source as well to eliminate any patients who were actually diagnosed before the study period.

When a patient was classified by the scan review as having a pituitary adenoma but did not have surgery, the clinical records were obtained to identify endocrinologically active tumours treated medically. When the clinical record documented established acromegaly, Cushing's disease, or prolactin concentrations greater than four times normal, the scan diagnosis was considered verified.

Some cases classified as meningiomas had not been operated on. It was thought that certain images were absolutely typical. These scans showed a uniformly enhancing smooth edged lesion with a broad dural base and a dural tail. When these patients had two scans more than a year apart within the study period without a change in size they were considered verified without histology.

Similarly, some cases classified as acoustic neuromas had characteristic scans consisting of a small enhancing lesion confined to or entering the internal auditory canal. When a patient had two scans a year apart with such a lesion unchanged in size during the study period they were considered verified.

A similar treatment was applied to certain cysts (colloid cysts and dermoid tumours). 
It was not thought that there was any alternative to pathological verification for neuroepithelial tumours or primary lymphomas.

SECONDARY SOURCES

Once verification of the primary source was complete, the database was matched to the secondary sources using standard techniques. ${ }^{7}$ The clinical records of all patients not appearing in the scan review were obtained to verify the diagnosis. Cases found at necropsy were noted but not included in the incidence figures. It was thought that these cases should not be included as they are most likely asymptomatic and do not use any health service resources.

Some patients appeared only in the scan review. Further checks were performed against the patient administration system to ensure that none had been admitted to hospital.

STATISTICAL ANALYSIS

Age and sex specific incidence rates for primary tumours with greater than 50 cases are presented. The denominator used was the population of Devon and Cornwall taken as the average of the mid-year estimates for the study period in mid-decade age bands. Summary rates are standardised by the direct method to the population of England and Wales (1991 United Kingdom Census). Confidence intervals were generated by assuming that the counts followed a Poisson distribution. Groups were compared by Student's $t$ test and the $\chi^{2}$ test for continuous variables and proportions, respectively. Data handling was performed using Microsoft Access V 7.0 and analysis carried out with Microsoft Excel V 7.0 and SPSS V 8.0 on a personal computer.

\section{Results}

PRIMARY SOURCE

The figure summarises the results of the scan review. A total of 16923 scan reports were reviewed. In the abnormal group, 1344 patients (other) had scans for reasons not relevant to this study. These included patients scanned

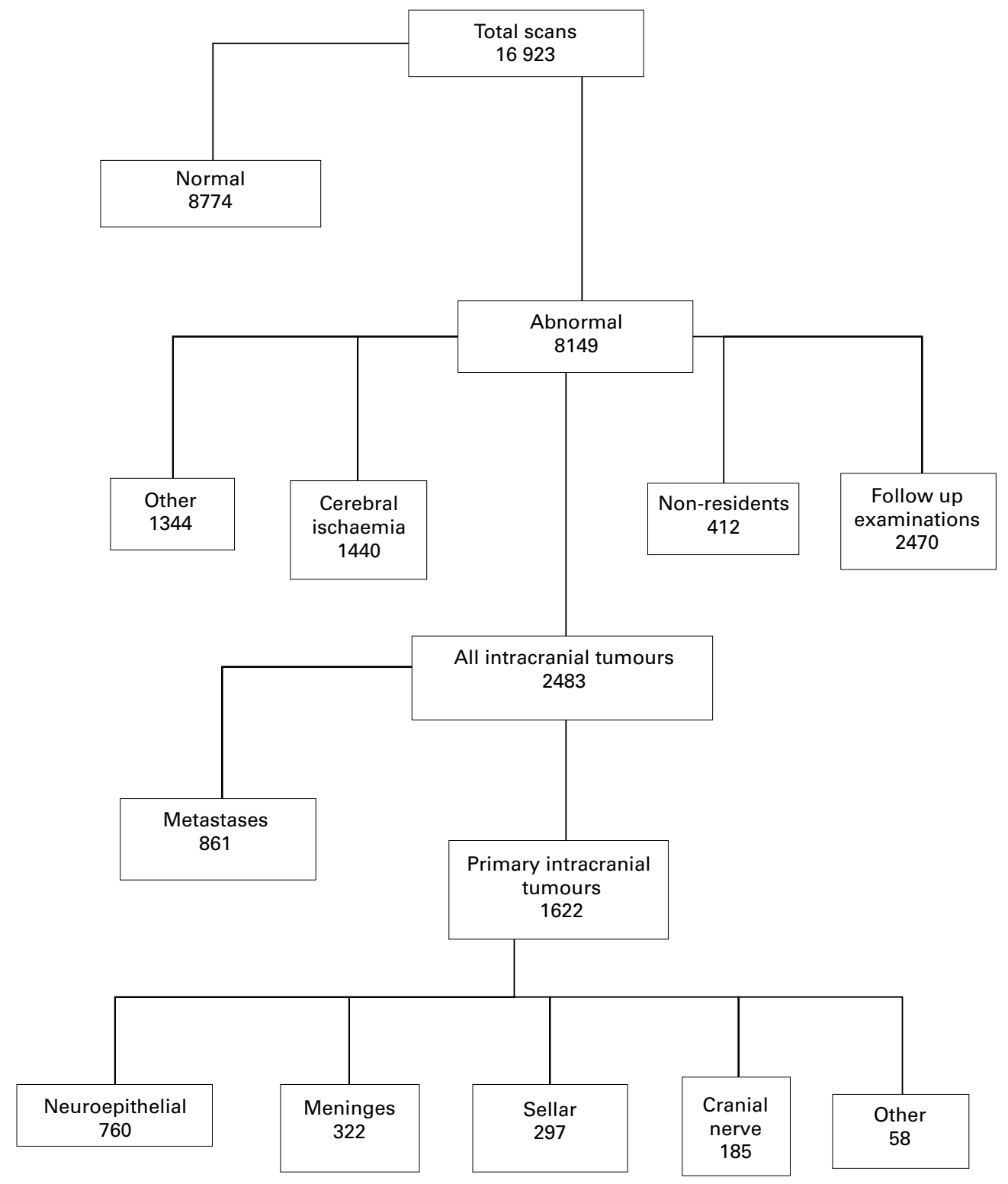

Summary of scan results. 
Table 1 Number of incident tumours and \% verified

\begin{tabular}{|c|c|c|c|c|}
\hline Diagnosis & $\mathrm{No}^{*}$ & $\begin{array}{l}\text { Histologically } \\
\text { verified }(\%)\end{array}$ & Other (\%) & $\begin{array}{l}\text { Total } \\
\text { verified (\%) }\end{array}$ \\
\hline Neuroepithelial & $779(19)$ & 69.45 & 0.00 & $69.45 \%$ \\
\hline Astrocytoma & 710 & & & \\
\hline Ependymomal & 27 & & & \\
\hline Embryonal & 25 & & & \\
\hline Pineal & 10 & & & \\
\hline Oligodendroglial & 7 & & & \\
\hline Meningeal & $332(10)$ & 76.51 & 5.72 & 82.23 \\
\hline Meningioma & 302 & & & \\
\hline Haemangioblastoma & 19 & & & \\
\hline Sellar & $301(4)$ & 61.06 & 32.67 & 93.73 \\
\hline Pituitary adenoma & 282 & & & \\
\hline Craniopharyngioma & 19 & & & \\
\hline Cranial nerve & $190(5)$ & 58.42 & 16.32 & 74.74 \\
\hline Lymphoma & 29 & 58.62 & 0.00 & 58.62 \\
\hline Cysts & $29(8)$ & 66.67 & 11.11 & 77.78 \\
\hline Extensions & 5 & 20.00 & 0.00 & 20.00 \\
\hline Germ cell & 3 & 66.00 & 0.00 & 66.00 \\
\hline All primary tumours & $1668(46)$ & 67.68 & 9.29 & 76.97 \\
\hline
\end{tabular}

^Total number (number added by secondary sources).

for otolaryngological and ophthalmalogical indications, multiple sclerosis, and cerebral haemorrhage.

A total of 2483 patients had their first diagnostic scan showing an intracranial tumour. The largest group of 861 had metastases $(34 \%)$. Considering only the 1622 primary intracranial tumours, there were $760(47 \%)$ neuroepithelial tumours, $322(20 \%)$ tumours of the meninges, 297 (18\%) sellar tumours, and $185(11 \%)$ tumours of cranial nerves. There were 29 lymphomas, 21 cysts and tumour-like lesions, five local extensions, and three germ cell tumours.

\section{VERIFICATION}

Overall $65.9 \%$ of patients classified as having primary intracranial tumours by the scan review underwent surgery. The frequency of surgical intervention varied from $76 \%$ of patients between 45 and 54 years of age to $42 \%$ of those over 75 . Histological verification also varied by diagnosis from $58.6 \%$ for lymphomas to $76.1 \%$ for tumours of the meninges. Table 1 gives the total number of incident tumours from all sources and the percentage verification for each type. The "other" category refers to endocrinological verification in the case of sellar tumours and radiological verification in relation to cranial nerve tumours, tumours of the meninges, and cysts.

A total of 99 patients (36\%) had pituitary adenomas which were endocrinologically active but did not have surgery, 74 of these were prolactinomas; $17.4 \%$ of acoustic neuromas were small, not thought to require surgery, and were unchanged on two scans a year apart. Of the 75 patients considered to have meningiomas who did not undergo surgery, 18 were verified by their radiological appearance.

Of the 861 patients classified by the scan review as metastases only $135(15.7 \%)$ were histologically verified.

\section{DIAGNOSTIC ACCURACY}

A total of 1123 of the patients classified as having primary tumours by the scan review had histological verification. Twenty nine of these were miscoded. Table 2 shows the number misclassified and the percentage of correct diagnoses. All cranial nerve tumours were cor-
Table 2 Number of incorrect diagnoses in the scan review and \% correct diagnoses for the 1123 histologically verified cases

\begin{tabular}{lccr}
\hline Diagnosis & $\begin{array}{l}\text { Histologically } \\
\text { verified }\end{array}$ & $\begin{array}{l}\text { No } \\
\text { incorrect }\end{array}$ & \multicolumn{1}{c}{$\begin{array}{c}\% \\
\text { Correct }\end{array}$} \\
\hline Neuroepithelial & 540 & 12 & $97.78 \%$ \\
Meningeal & 259 & 14 & $94.59 \%$ \\
Sellar & 180 & 1 & $99.44 \%$ \\
Cranial nerve & 107 & 0 & $100.00 \%$ \\
Lymphoma & 19 & 2 & $89.47 \%$ \\
Cysts & 15 & 0 & $100.00 \%$ \\
Germ cell & 2 & 0 & $100.00 \%$ \\
Extensions & 1 & 0 & $100.00 \%$ \\
All primary tumours & 1123 & 29 & $97.41 \%$ \\
\hline
\end{tabular}

rectly classified. Of the 29 miscoded there were, in total, 17 false positives; 12 metastases, two aneurysms, two cavernous angiomata, and one subdural haematoma. The other errors were mistaking one type of primary tumour for another.

For the 1123 histologically verified primary tumours, overall diagnostic accuracy was $97.4 \%$ (95\% CI $96.3 \%-98.3 \%)$. Accepting the non-histological verification of meningioma, acoustic neuroma, cysts and pituitary adenoma, there were 379 primary tumours from the scan review which were unverified. Assuming the same accuracy for the non-verified patients it is possible that a further $10(95 \% \mathrm{CI}$ 7-14) patients have been misclassified.

Diagnostic accuracy for metastases was considerably worse. Of the 135 patients histologically verified $23(17.0 \%)$ were primary tumours. Assuming the same accuracy for the unverified metastases it is possible that a further 123 patients may actually have had primary tumours. In total there were 24 false negatives including one other patient who was thought in the scan review to have an aneurysm but actually had a pituitary adenoma.

\section{SECONDARY SOURCES}

The primary source was first matched with the data from the South and West Cancer Intelligence Unit. Nine hundred and thirty four registrations with primary intracranial tumour were notified to the unit during the study period, of which 93 did not appear in the scan review. Twenty two of these cases were actually incident before the study period due to delays in registration. In 21 cases the diagnosis was made on the basis of a non-contrasted CT only and the clinical records did not provide sufficient information to determine the true nature of the illness. These patients have not been included. Nine patients did not have an intracranial tumour. The records of two patients could not be found. Nineteen cases were diagnosed at necropsy, 10 astrocytomas, six meningiomas, and one each of metastasis, acoustic neuroma, and pituitary adenoma. Twenty patients were included in the final combined database, 12 of which were histologically verified. The reasons these patients were not in the scan review were as follows: nine patients had CT scans which were incorrectly coded by the $x$ ray technician as without contrast, five were missing for unknown reasons, four had no report and their scans could not be found for review, and two became ill and were scanned while outside the region. 
Table 3 Age and sex specific incidence rates for all primary tumours and for the four categories with more than 50 cases.

\begin{tabular}{|c|c|c|c|c|c|c|c|c|c|c|}
\hline \multirow[b]{2}{*}{ Diagnosis } & \multirow[b]{2}{*}{ Sex } & \multicolumn{8}{|l|}{ Age } & \multirow[b]{2}{*}{ Total } \\
\hline & & $0-14$ & $15-24$ & $25-34$ & $35-44$ & $45-54$ & $55-64$ & $65-74$ & $>75$ & \\
\hline Cranial nerves & $\mathrm{F}$ & $\begin{array}{l}0.0 \\
(0-0)\end{array}$ & $\begin{array}{l}0.9 \\
(0.2-2.2)\end{array}$ & $\begin{array}{l}1.2 \\
(0.4-2.7)\end{array}$ & $\begin{array}{l}2.0 \\
(0.9-3.5)\end{array}$ & $\begin{array}{l}2.9 \\
(1.5-4.9)\end{array}$ & $\begin{array}{l}5.9 \\
(3.8-8.7)\end{array}$ & $\begin{array}{l}5.7 \\
(3.6-8.3)\end{array}$ & $\begin{array}{l}1.6 \\
(0.6-3.2)\end{array}$ & $\begin{array}{l}2.33 \\
(1.28-3.98)\end{array}$ \\
\hline Cranial nerves & M & $\begin{array}{l}0.0 \\
(0-0)\end{array}$ & $\begin{array}{l}0.4 \\
(0.0-1.5)\end{array}$ & $\begin{array}{l}1.1 \\
(0.3-2.4)\end{array}$ & $\begin{array}{l}1.8 \\
(0.8-3.4)\end{array}$ & $\begin{array}{l}5.3 \\
(3.3-7.9)\end{array}$ & $\begin{array}{l}6.1 \\
(3.9-9.1)\end{array}$ & $\begin{array}{l}7.6 \\
(5.0-11.0)\end{array}$ & $\begin{array}{l}4.1 \\
(1.9-7.5)\end{array}$ & $\begin{array}{l}2.44 \\
(1.42-4.04)\end{array}$ \\
\hline Meningeal & $\mathrm{F}$ & $\begin{array}{l}0.0 \\
(0-0)\end{array}$ & $\begin{array}{l}1.1 \\
(0.3-2.5)\end{array}$ & $\begin{array}{l}1.4 \\
(0.5-2.9)\end{array}$ & $\begin{array}{l}3.1 \\
(1.7-5.0)\end{array}$ & $\begin{array}{l}7.6 \\
(5.2-10.6)\end{array}$ & $\begin{array}{l}8.5 \\
(5.9-11.7)\end{array}$ & $\begin{array}{l}14.1 \\
(10 .-18.0)\end{array}$ & $\begin{array}{l}10.6 \\
(7.7-14.0)\end{array}$ & $\begin{array}{l}4.83 \\
(3.32-6.89)\end{array}$ \\
\hline Meningeal & M & $\begin{array}{l}0.2 \\
(0.0-0.8)\end{array}$ & $\begin{array}{l}0.2 \\
(0.0-1.2)\end{array}$ & $\begin{array}{l}1.2 \\
(0.4-2.7)\end{array}$ & $\begin{array}{l}1.4 \\
(0.5-2.8)\end{array}$ & $\begin{array}{l}3.4 \\
(1.8-5.5)\end{array}$ & $\begin{array}{l}4.7 \\
(2.8-7.2)\end{array}$ & $\begin{array}{l}9.1 \\
(6.4-12.3)\end{array}$ & $\begin{array}{l}8.1 \\
(5.6-11.1)\end{array}$ & $\begin{array}{l}3.09 \\
(1.90-4.99)\end{array}$ \\
\hline Neuroepithelial & $\mathrm{F}$ & $\begin{array}{l}5.3 \\
(3.6-7.3)\end{array}$ & $\begin{array}{l}2.9 \\
(1.6-4.9)\end{array}$ & $\begin{array}{l}4.8 \\
(3.0-7.2)\end{array}$ & $\begin{array}{l}7.0 \\
(4.8-9.7)\end{array}$ & $\begin{array}{l}10.1 \\
(7.3-13.5)\end{array}$ & $\begin{array}{l}16.1 \\
(12 .-20.5)\end{array}$ & $\begin{array}{l}19.4 \\
(15 .-24.6)\end{array}$ & $\begin{array}{l}21.7 \\
(16 .-28.4)\end{array}$ & $\begin{array}{l}8.23 \\
(5.95-11.16)\end{array}$ \\
\hline Neuroepithelial & M & $\begin{array}{l}4.5 \\
(3.0-6.4)\end{array}$ & $\begin{array}{l}4.6 \\
(2.8-6.9)\end{array}$ & $\begin{array}{l}5.9 \\
(3.9-8.5)\end{array}$ & $\begin{array}{l}8.8 \\
(6.3-11 .)\end{array}$ & $\begin{array}{l}12.4 \\
(9.3-16.1)\end{array}$ & $\begin{array}{l}23.5 \\
(18.9-28.7)\end{array}$ & $\begin{array}{l}30.4 \\
(25.0-36.8)\end{array}$ & $\begin{array}{l}27.1 \\
(20.9-34.4)\end{array}$ & $\begin{array}{l}11.57 \\
(8.77-15.06)\end{array}$ \\
\hline Sellar & $\mathrm{F}$ & $\begin{array}{l}0.2 \\
(0.0-0.8)\end{array}$ & $\begin{array}{l}3.8 \\
(2.2-5.9)\end{array}$ & $\begin{array}{l}6.3 \\
(4.2-9.0)\end{array}$ & $\begin{array}{l}9.2 \\
(6.7-12 .)\end{array}$ & $\begin{array}{l}4.8 \\
(2.9-7.3)\end{array}$ & $\begin{array}{l}4.1 \\
(2.3-6.6)\end{array}$ & $\begin{array}{l}6.2 \\
(3.8-9.3)\end{array}$ & $\begin{array}{l}3.7 \\
(1.6-7.0)\end{array}$ & $\begin{array}{l}4.26 \\
(2.74-6.42)\end{array}$ \\
\hline Sellar & M & $\begin{array}{l}0.5 \\
(0.0-1.3)\end{array}$ & $\begin{array}{l}1.0 \\
(0.3-2.4)\end{array}$ & $\begin{array}{l}2.9 \\
(1.6-4.9)\end{array}$ & $\begin{array}{l}3.7 \\
(2.1-5.8)\end{array}$ & $\begin{array}{l}3.4 \\
(1.9-5.6)\end{array}$ & $\begin{array}{l}9.2 \\
(6.4-12.7)\end{array}$ & $\begin{array}{l}10.1 \\
(7.1-14.0)\end{array}$ & $\begin{array}{l}5.7 \\
(3.1-9.6)\end{array}$ & $\begin{array}{l}3.73 \\
(2.28-5.88)\end{array}$ \\
\hline All primary & $\mathrm{F}$ & $\begin{array}{l}5.7 \\
(4.0-7.9)\end{array}$ & $\begin{array}{l}9.3 \\
(6.7-12.5)\end{array}$ & $\begin{array}{l}14.7 \\
(11.4-18.5)\end{array}$ & $\begin{array}{l}21.9 \\
(18.1-26.4)\end{array}$ & $\begin{array}{l}26.3 \\
(21.8-31.6)\end{array}$ & $\begin{array}{l}34.0 \\
(28.7-40.1)\end{array}$ & $\begin{array}{l}41.6 \\
(35.8-48.1)\end{array}$ & $\begin{array}{l}26.5 \\
(22.0-31.8)\end{array}$ & $\begin{array}{l}20.24 \\
(16.61-24.60)\end{array}$ \\
\hline & M & $\begin{array}{l}5.3 \\
(3.6-7.3)\end{array}$ & $\begin{array}{l}6.5 \\
(4.4-9.2)\end{array}$ & $\begin{array}{l}12.2 \\
(9.2-15.7)\end{array}$ & $\begin{array}{l}16.6 \\
(13.1-20.5)\end{array}$ & $\begin{array}{l}25.5 \\
(21.0-30.7)\end{array}$ & $\begin{array}{l}46.4 \\
(40.0-53.8)\end{array}$ & $\begin{array}{l}61.7 \\
(50.7-73.3)\end{array}$ & $\begin{array}{l}52.1 \\
(43.5-62.1)\end{array}$ & $\begin{array}{l}21.88 \\
(17.78-26.69)\end{array}$ \\
\hline
\end{tabular}

Values are incidence/100000 person-years (95\% CI)

Matching the primary source with the operative database from Plymouth disclosed 26 patients, all histologically verified. Six of these cases were colloid cysts which are generally diagnosed on non-contrasted CT and three were patients with endocrinologically active pituitary adenomas who had normal scans. A further seven had scans which were incorrectly coded as non-contrasted.

Matching with the admission and pathology databases from Plymouth and Bristol showed two further patients diagnosed at necropsy, both with meningiomas.

A total of 1265 cases were found in more than one source. Twenty one per cent (357) were found only by the scan review. None of these 357 appeared in any of the secondary sources and further checks showed that although some had been seen in outpatient clinics none had been admitted to hospital in Plymouth or Bristol at the time of their scans. It is possible that some patients may have been admitted to other hospitals in the region but it is very unlikely that more than a handful would have been treated without biopsy, which would have only been available at Bristol or Plymouth.

Including the data from secondary sources there were 70 false negatives in the scan review. The sensitivity of the scan review was therefore $93.8 \%$.

INCIDENCE

Table 3 presents the age and sex specific incidence rates for all primary tumours and the four categories which had more than 50 cases. All tumours except sellar tumours in females showed a general rise in incidence after the age of 45. Sellar tumours were more common in females under the age of 55 and there was a peak at age 35 to 44 consisting mainly of prolactinomas. In this age group the confidence interval did not overlap with that of males. The rates for meningeal tumours were higher in females for all age groups except those over 75 . Between 35 and 64 the female rates were twice as high. Neuroepithelial tumours were the commonest primary tumour in all age groups.
For those patients over the age of 54 years the male rates for these tumours were significantly higher than female rates. The summary rate for all primary tumours was higher in females below the age of 45 because of the preponderance of meningiomas and pituitary adenomas. After age 45, tumours were more common in males and above the age of 65 the confidence intervals did not overlap.

The total column in table 3 presents age adjusted incidence rates per 100000 personyears (standardised by the direct method to the population of England and Wales).

\section{CASE DISPOSITION}

Overall $70 \%$ of males were operated on and $65.3 \%$ of females $\left(\chi^{2}=4.269, \mathrm{p}=0.039\right)$. When the cohort was analysed without the inclusion of pituitary adenomas this difference disappeared $(68.8 \%$ for males and $69.7 \%$ for females $\left.\left(\chi^{2}=0.140, p=0.709\right)\right)$. A total of $76.4 \%$ of males with pituitary adenomas had operations but only $47.2 \%$ of females. For tumours other than pituitary adenoma there were no between sex differences in operative proportions.

For the whole cohort the average age of the operated group was significantly lower than those not operated on (mean 52.8 (SD 19.4) years $v$ mean 59.7 (SD 19.6), respectively $(t=6.71, \mathrm{p}<0.0005)$. This difference was even more striking if the cohort was analysed without the pituitary adenomas. In this case the mean age of the operated patients was 52.5 (SD 19.7) years and for the unoperated patients it was 64.1 (SD 17.9) $(t=10.41$, $\mathrm{p}<0.0005)$.

In total, $79 \%$ of the cohort was admitted to Plymouth or Bristol. Least likely to be admitted were patients with acoustic neuromas $(66 \%)$ or sellar tumours $(67 \%)$.

\section{Discussion}

This study has found higher brain tumour incidence rates than any previous study in the United Kingdom by using as a primary source a 5 year audit of CT and MRI of the head done in Devon and Cornwall. This population was 
Table 4 Comparison of Devon and Cornwall rates with those from Lothian and the cancer registry. Rates are standardised to the population of England and Wales (1991 census)

\begin{tabular}{|c|c|c|c|c|c|c|}
\hline \multirow[b]{2}{*}{ Diagnosis } & \multicolumn{2}{|c|}{ Lothian } & \multicolumn{2}{|c|}{ Devon and Cornwall } & \multicolumn{2}{|c|}{ Cancer Intelligence Unit } \\
\hline & No & Rate & No & Rate & No & Rate \\
\hline Neuroepithelial & 122 & $8.49(4.83-14.09)$ & 778 & $9.83(7.3-13.00)$ & 584 & $7.24(5.16-9.98)$ \\
\hline Meningeal & 45 & $3.10(1.23-4.04)$ & 333 & $3.99(2.68-5.97)$ & 166 & $1.96(1.14-3.29)$ \\
\hline Sellar & 38 & $2.47(0.92-6.14)$ & 303 & $3.99(2.52-6.15)$ & 122 & $1.54(0.74-2.94)$ \\
\hline Cranial nerves & 10 & $0.71(0.13-3.47)$ & 190 & $2.38(1.35-4.00)$ & 63 & $0.78(0.27-1.86)$ \\
\hline All primary & 228 & $15.67(10.47-22.76)$ & 1668 & $21.04(17.18-25.62)$ & & \\
\hline
\end{tabular}

Rates are incidence/ 100000 person-years $(95 \% \mathrm{CI})$.

stable over the study period and geographically isolated. A careful verification process ensured diagnostic accuracy and elimination of all patients who were not incident cases. Secondary sources were shown to add very few additional cases

\section{STUDY LIMITATIONS}

This study's rate of histological verification $(67.7 \%)$ was lower than that reported in other studies. Augmented significantly by a $60 \%$ necropsy rate, Kurland et al from the Mayo Clinic reported $91 \%$ histological verification. ${ }^{8}$ Histology recorded in registry studies varies from $85 \%$ to $72.8 \% .^{9}{ }^{10}$

It was not the intention of this study to examine the accuracy of scan diagnoses. The scan review was, in the main, retrospective and the accuracy rates found here may not be repeatable in a prospective study. In 1979, Kendall et $a l^{11}$ reported a series of 314 histologically established gliomas of all types scanned on an EMI 1010 machine. They found 26 cases misclassified for an overall accuracy of $91.8 \%$. Todd et $a l^{12}$ reported on 44 histologically established gliomas scanned on either a GE 8800 or an EMI 1010 machine. That group found three patients were misclassified $(92.5 \%$ accuracy). In the same series, $50 \%$ of scans considered to show a metastasis were actually gliomas. In the present study the accuracy rate for metastasis was $83 \%$. All our cases were scanned on either third generation CT machines or by MRI. It is not unreasonable to suggest that the increased resolution provided by these modern machines has allowed a better diagnostic accuracy rate. Overall it would seem most likely that the incidence rates presented here are an underestimate in view of the fact that the scan review produced 24 false negatives out of 861 and only 17 false positives out of 1123 . It is more likely that an unverified metastasis was a primary tumour than the reverse.

In the scan review, 29 out of 1123 histologically verified tumours were incorrectly classified. Allowing for certain assumptions about the imaging and growth characteristics of meningioma and acoustic neuroma (49 patients radiologically verified), it is unlikely that any more than a further 14 patients were miscoded. If these assumptions are rejected only two further patients would have been misclassified.

STUDY COMPARISONS

Table 4 compares the incidence rates found in Devon and Cornwall with those from the Cancer Registry and from Lothian which, until this study, were the highest in the United
Kingdom. ${ }^{4}$ The rate for all primary tumours in Devon and Cornwall is $25 \%$ higher than the Scottish rate. The rates for neuroepithelial and meningeal tumours are comparable. The Lothian rates are $40 \%$ and $70 \%$ lower for sellar and cranial nerve tumours respectively. The Scottish study did not use MRI as a source of case ascertainment and these two tumours are ones in which MRI has made the largest impact. It has become increasingly recognised that many people with deafness harbour small acoustic neuromas. Brain MRI is the only way to image some of these small tumours. Perhaps equally important in explaining the discrepancy, the Lothian group found that only $12 \%$ of patients had not been admitted to hospital whereas in the present cohort $21 \%$ of patients were not admitted to hospital. Examination of the cases not admitted showed that $80 \%$ were benign tumours treated medically (prolactinomas and low grade gliomas) or meningeal and cranial nerve tumours in elderly people which were followed up without surgery. In the malignant group not admitted there was also a predominance of elderly people.

The rates from the present study were twice as high for meningeal and sellar tumours and three times higher for cranial nerve tumours than the figures from the South and West Regional Cancer Intelligence Unit. No rate was calculated for all primary tumours as the registry does not attempt to collect information on some of the rarer tumours. Nevertheless there would seem to be significant underregistration of certain types of tumour, especially in the benign categories.

\section{CASE DISPOSITION}

This study presents data which suggest that $21 \%$ of incident cases are not admitted to hospital. The two groups least likely to be admitted are those with sellar and cranial nerve tumours. The group of sellar tumours contains a significant proportion of young females with prolactinomas which are treated medically. Increasing numbers of small acoustic neuromas are being discovered in people with deafness and many are followed up or treated with stereotactic radiotherapy rather than operated on. The mean age of people admitted is significantly lower than those not admitted.

There is evidence that the incidence of brain tumours is increasing internationally especially in the older age group. ${ }^{13}$ Some have argued that this is due to changing attitudes to investigation of elderly people ${ }^{14}$ and there is some evidence that the rate of CT scanning in elderly people has increased. ${ }^{15}$ In view of this, it is to be 
expected that many older people will be diagnosed with brain tumours but will either be thought to be too ill or not ill enough to benefit from hospital treatment. It could therefore be argued that the lower rate of pathological verification in this study is a strength and not a weakness and evidence of better case finding methods.

CASE FINDING SOURCES

Counsell and Grant ${ }^{5}$ have argued that studies with multiple case finding strategies produce the highest incidence rates. This investigation has shown that only 46 out of 1668 primary tumours were missed by the scan review. In total, 15 patients were missed because their CT was incorrectly coded as non-contrast and nine further cases were not found for other technical reasons. Six colloid cysts were legitimately diagnosed on non-contrasted CT and only three patients (pituitary adenomas) were diagnosed by non-imaging methods. All of the technical failures and the missed colloid cysts would not have occurred if the exercise had been carried out prospectively.

\section{Conclusion}

In the modern age, imaging of the brain has become necessary, and is sufficient, for the diagnosis of brain tumours. An audit of CT and MRI results provides an excellent method for estimation of the incidence of brain tumours and this study suggests that a nationwide prospective audit of scan results would produce virtually complete case ascertainment. These methods are particularly suitable for a system such as the National Health Service and may be less applicable in developing countries and those with a fee for service system. A question must remain about diagnostic accuracy but an accuracy rate of at least $90 \%$ to $93 \%$ is achievable and along with verification from operative and pathology databases would produce highly precise information. The only supplementary source that needs to be considered is an audit of endocrinology clinics.

We thank Mr Pobereskin's secretary, Judy Beaumont, for her tireless support of this project and Dr JR Sneyd for his helpful comments on the manuscript.
Appendix

List of brain tumours selected for registration by the South and West Cancer Intelligence Unit

\begin{tabular}{|c|c|}
\hline $\begin{array}{l}\text { ICD-10 } \\
\text { Code }\end{array}$ & Cell type \\
\hline $8000 / 3$ & Neoplasm, uncertain whether benign or malignant \\
\hline $8000 / 3$ & Neoplasm, malignant \\
\hline $8140 / 0$ & Pituitary adenoma \\
\hline 9350/1 & Craniopharyngioma \\
\hline $9380 / 3$ & Glioma, malignant \\
\hline $9381 / 3$ & Gliomatosis, cerebri \\
\hline $9382 / 3$ & Mixed glioma \\
\hline $9383 / 3$ & Subependymal glioma \\
\hline $9384 / 1$ & Subependymal giant cell astrocytoma \\
\hline $9390 / 0$ & Choroid plexus papilloma \\
\hline $9390 / 3$ & Choroid plexus papilloma, malignant \\
\hline $9391 / 3$ & Ependymoma \\
\hline $9392 / 3$ & Ependymoma, anaplastic \\
\hline $9391 / 1$ & Papillary ependymoma \\
\hline $9394 / 1$ & Myxopapillary ependymoma \\
\hline $9400 / 3$ & Astrocytoma \\
\hline $9401 / 3$ & Astrocytoma, anaplastic \\
\hline $9410 / 3$ & Protoplasmic astrocytoma \\
\hline $9411 / 3$ & Gemistocytic astrocytoma \\
\hline $9420 / 3$ & Fibrillary astrocytoma \\
\hline $9421 / 3$ & Pilocytic astrocytoma \\
\hline $9422 / 3$ & Spongioblastoma \\
\hline $9424 / 3$ & Spongioblastoma, polare \\
\hline $9424 / 3$ & Pleomorphic xanthoastrocytoma \\
\hline $9430 / 3$ & Astroblastoma \\
\hline $9440 / 3$ & Glioblastoma \\
\hline $9441 / 3$ & Giant cell glioblastoma \\
\hline $9442 / 3$ & Gliosarcoma \\
\hline $9443 / 3$ & Primitive polar spngioblastoma \\
\hline $9450 / 3$ & Oligodendroglioma \\
\hline $9451 / 3$ & Oligodendroglioma, anaplastic \\
\hline $9460 / 3$ & Oligodendroblastoma \\
\hline $9470 / 3$ & Medulloblastoma \\
\hline $9471 / 3$ & Desmoplastic medulloblastoma \\
\hline $9472 / 3$ & Medullomyoblastoma \\
\hline $9473 / 3$ & Primitive neuroectodermal tumour \\
\hline $9480 / 3$ & Cerebellar sarcoma \\
\hline $9481 / 3$ & Monstrocellular sarcoma \\
\hline $9490 / 3$ & Ganglioneuroblastoma \\
\hline $9500 / 3$ & Neuroblastoma \\
\hline $9501 / 3$ & Medulloepithelioma \\
\hline $9520 / 3$ & Teratoid medulloepithelioma \\
\hline $9503 / 3$ & Neuroepithelioma \\
\hline $9504 / 3$ & Spongioneuroblastoma \\
\hline $9505 / 1$ & Ganglioglioma \\
\hline $9506 / 0$ & Neurocytoma \\
\hline $9530 / 0$ & Meningioma NOS \\
\hline $9530 / 1$ & Meningiomatosis \\
\hline $9530 / 3$ & Meningioma, malignant \\
\hline $9531 / 0$ & Meningotheliomatis meningioma \\
\hline $9532 / 0$ & Fibrous meningioma \\
\hline $9533 / 0$ & Psammomatous meningioma \\
\hline $9534 / 0$ & Angiomatous meningioma \\
\hline $9535 / 0$ & Haemangioblastic meningioma \\
\hline $9536 / 0$ & Haemangiopericytic meningioma \\
\hline $9537 / 0$ & Transitional meningioma \\
\hline $9538 / 1$ & Papillary meningioma \\
\hline $9539 / 3$ & Meningeal sarcomatosis \\
\hline $9540 / 0$ & Neurofibroma \\
\hline $9541 / 0$ & Melanotic neurofibroma \\
\hline $9550 / 0$ & Plexiform neurofibroma \\
\hline $9560 / 0$ & Neurilemmoma \\
\hline $9570 / 0$ & Neuroma \\
\hline
\end{tabular}

^Equivalent ICD-9 codes used before April, 1994.

1 Brewis M, Poskanzer DC, Roland C, et al. Neurological disease in an English city. Acta Neurol Scand 1966;42(suppl ease in an

24):41-6

Barker DJP, Weller RO, Garfield JS. Epidemiology of primary tumours of the brain and spinal cord: a regional survey in southern England. F Neurol Neurosurg Psychiatry 1976;39:290-6

3 Cole CC, Wilkins PR, West RR. An epidemiological survey of primary tumours of the brain and spinal cord in south east Wales. Br F Neurosurg 1989;3:487-94.

4 Counsell CE, Collie DA, Grant R. Incidence of intracranial tumours in the Lothian Region of Scotland, 1989-90. F Neurol Neurosurg Psychiatry 1996;61:143-50.

5 Counsell CE, Grant R. Incidence studies of primary and secondary intracranial tumors: a systematic review of their methodology and results. F Neuro-Oncology 1998;37:24150 .

6 Kleihues P, Burger PC, Scheithauer BW. World Health Organisation international histological classification of tumours. Organisation international histological classification of tumours. Histological typing of tumours of Berlin: Springer-Verlag, 1993. 
7 Gill L, Goldacre M, Simmons H, et al. Computerised linking of medical records: methological guidelines. $\mathcal{F}$ Epidemio Commity Health 1993;47:316-19.

8 Kurland LT, Schoenberg BS, Annegers JF, et al. The incidence of primary intracranial neoplasms in Rochester, Minnesota, 1935-77. Ann N Y Acad Sci 1982;381:6-16.

9 Davis FG, Malinski N, Haenszel W, et al. Primary brain tumor incidence rates in four United States regions, 1985-9: a pilot study. Neuroepidemiology 1996;15:103-12.

10 Tola MR, Casetta I, Granieri E, et al. Intracranial gliomas in Ferrara, Italy, 1976-91. Acta Neurol Scand 1994;90:312-17.

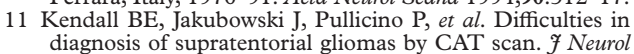
Neurosurg Psychiatry 1979;42:485-92.
12 Todd NV, McDonagh T, Miller JD. What follows diagnosis by computed tomography of solitary brain tumour? Lancet 1987;i:611-12.

13 Davis DL, Ahlbom A, Hoel D, et al. Is brain cancer mortality increasing in industrialised countries? Am f Ind Med 1991;19:421-31.

14 Helseth A. The incidence of primary central nervous system neoplasms before and after computerized tomography availability. $\mathcal{F}$ Neurosurg 1995;83:999-1003.

15 Asplund K, Rajakangas A-M, Kuulasmaa K, et al. Multinational comparison of diagnostic procedures and management of acute stroke: the WHO MONICA study. Cerebrovascular Diseases 1996;6:66-74.

\section{NEUROLOGICAL STAMP}

\section{Andre Högyes (1847-1906)}

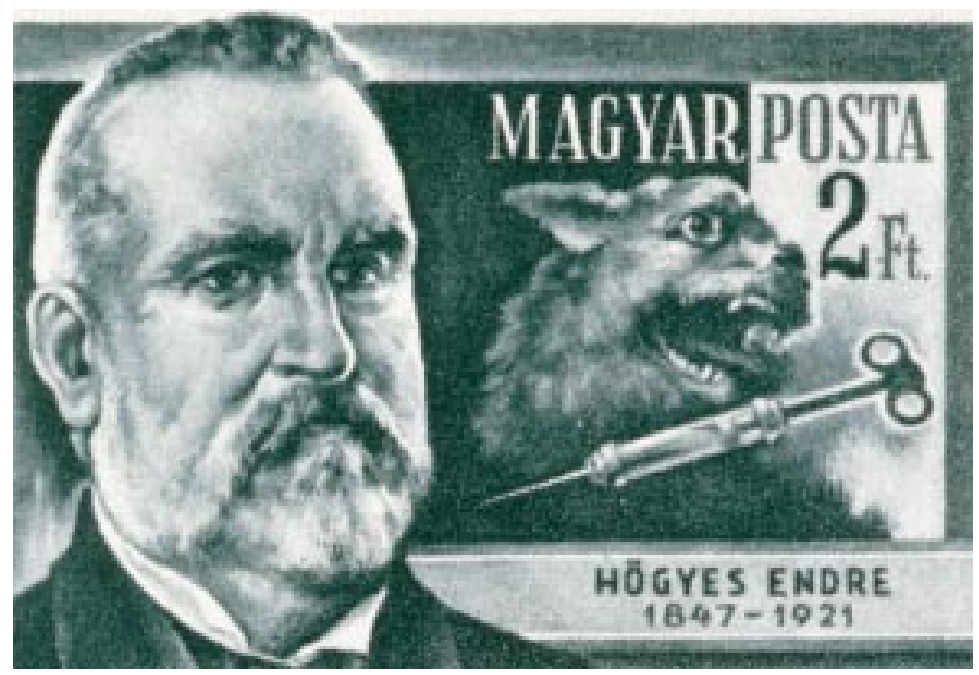

Högyes studied medicine at the University of Budapest and received his degree in 1870 . From 1875 to 1883 he was Professor of Pathology and Therapeutics at the University of Kolosvar and was at various times Rector of the Faculty and Rector of the Medical Department at Budapest University. After Pasteur's success in developing a vaccination for rabies, the Research Institute of Rabies was established at Budapest by Högyes. Antirabies serum was manufactured at the Institute and he contributed to the treatment of this dreaded disease. Högyes was awarded the Hungarian Medical Academy prize for this contribution. He was internationally known and in 1954 was postally honoured with other scientists by Hungary as a great physician and scientist (Stanley Gibbons 1397, Scott 1108). 